\title{
Tempo da leitura silenciosa e em voz alta com jovens, envelhescentes e pessoas da terceira idade
}

\author{
Silent reading time and reading aloud with young, older adults and elderly people \\ Maria Augusta Rocha Porto \\ Raquel Meister Ko. Freitag \\ Julian Tejada \\ Universidade Federal de Sergipe, São Cristóvão, SE, Brasil
}

\begin{abstract}
Resumo: Este estudo visa aferir o tempo de leitura, em português e em inglês, de modo silencioso e em voz alta, e o controle do movimento ocular (quantidade e duração das fixações e regressões), com três grupos experimentais (10 de cada): jovens, envelhescentes e terceira idade, com o uso de aparelho de eye-tracking EyeTribe. Os resultados apontam que o grupo de participantes jovens se diferenciou dos outros dois grupos, com tempo de 200 a $250 \mathrm{~ms}$. O grupo de jovens obteve um tempo maior no inglês do que na leitura em português. Os participantes da terceira idade apresentaram um número muito maior estabelecido ao padrão de leitura de $500 \mathrm{~ms}$, apresentando um valor de 600-650ms. Nos textos de inglês, o tempo foi maior entre as três categorias. Os participantes leram os textos em inglês e em voz silenciosa mais rápido do que os textos em voz alta.
\end{abstract}

Palavras-chave: Tempo de leitura; Envelhecimento; Rastreamento ocular

\begin{abstract}
This study aims to measure the Portuguese and English reading time (in silent and reading aloud texts), as well as the eyetracking control (the amount and the number of fixations and regressions (go-past reading), with three different experimental groups (10 for each one of the groups): young, old, and aging-elderly people, using eye-tracker EyeTribe. The results showed that the young participant group differed from the other two groups, with the measure length time ranging from 200 to $250 \mathrm{~ms}$. The young participant group obtained a longer time in reading English than Portuguese. The elderly group showed a higher number than the established standard one of $500 \mathrm{~ms}$, averaging between 600-650 ms. In English texts, the reading time was longer in the three categories. The participants read English texts faster when reading silently than when reading aloud.
\end{abstract}

Keywords: Reading time; Aging; Eye tracking

\section{Introdução ${ }^{1}$}

A leitura é uma atividade complexa, que envolve coordenação rápida do processo visual. Antes da decodificação das letras, palavras, frases e texto, do reconhecimento da linguagem escrita de uma língua e da interpretação da sua estrutura, além dos processos cognitivos, existe um processo fisiológico. E, como todo processo fisiológico que acontece no ser humano, a leitura está sujeita aos efeitos do envelhecimento.

\footnotetext{
Este texto apresenta resultados do projeto "Formação de professores para o ensino de inglês na envelhescência e terceira idade", financiado pelo edital FAPITEC/SE/FUNTEC/CAPES № 07/2015 - NAPS linha 2.
}

O Brasil vive um processo de inversão demográfica, com a emergência de uma população em processo de envelhecimento. Em 2025, teremos uma maior quantidade de brasileiros na terceira idade do que crianças, conforme apontam as projeções do Instituto Brasileiro de Geografia e Estatística (IBGE, 2010). Esta situação requer que sejam repensadas políticas de formação de professores, por exemplo, na medida em que os envelhecentes ${ }^{2}$ e

\footnotetext{
2 Adotamos, para o escopo deste trabalho, a terminologia envelhescente (com SC, assim como nascer, crescer [e envelhescer]), que corresponde à pessoa entre as faixas etárias de $45 \mathrm{a} 60$ anos. Ao utilizarmos a palavra envelhescente, assumimos a postura de Mendes (2012), que inicialmente identificou o emprego da palavra para aquelas pessoas que estavam de braços abertos aos novos aprendizados.
} 
pessoas da terceira idade têm buscado oportunidades para a continuação de seus estudos. Uma ação que lida com esse público é o curso de extensão "A aula de inglês para a terceira idade" (PORTO, 2012), que tem como objetivo integrar alunos envelhecentes e da terceira idade da comunidade com alunos do curso de graduação em Letras Inglês da Universidade Federal de Sergipe, a fim de experienciar metodologias e aprendizagens da língua inglesa para este público específico.

Estudos evidenciam que aprender uma língua estrangeira é um exercício que pode mudar as conexões entre as diferentes áreas do cérebro relacionadas com a linguagem (BIALYSTOK, 2001; BIALYSTOK et al., 2006; SCHLEGEL et al. 2012; TOMITCH, 2013). Existem mais de 19 áreas relacionadas com a linguagem em cada hemisfério cerebral, embora a atividade delas seja predominantemente maior no hemisfério esquerdo (GLASSER; RILLING 2008, SCHLEGEL et al., 2012). Dentre elas, destacam-se duas áreas do córtex frontal (giro transverso frontopolar e giro transverso frontomarginal), que apresentam especial ativação em pessoas que aprendem uma segunda língua (SCHLEGEL et al., 2012). O córtex frontal é também responsável pela compreensão, que é a base da atenção e da realização das tarefas simultâneas (BIALYSTOK et al., 2006). Bialystok et al. (2006) evidenciam que, aumentando as conexões entre os dois hemisférios do cérebro, o ensino de uma segunda língua faz com que pessoas da terceira idade exercitem o cérebro e gerenciem a sua atenção o tempo inteiro, muito mais que os monolíngues, tornando-os cognitivamente mais eficientes. Bialystok et al. (2006) defendem que, do ponto de vista fisiológico e cognitivo, ser bilíngue só traz vantagem. Os bilíngues usam o lobo frontal como compensação do declínio da função medial; em termos de uso, isso significa que, no envelhecimento,

Pessoas que dominam mais de uma língua têm vantagens sobre as que dominam apenas uma. [... estudos indicam que idosos bilíngues, ou seja, que têm experiências ao longo da vida no uso de duas línguas diferentes, desenvolveram melhor a função executiva e a memória de trabalho, que podem ser usadas mais efetivamente para o processamento de linguagem, do que idosos monolíngues. [...] A fim de superar dificuldades de nomeação, tanto monolíngues quanto bilíngues podem fazer uso de diferentes estratégias, como evitar a palavra, reformulação da frase ou circunlocuções. Já idosos bilíngues podem também tomar de empréstimo palavras da outra língua ou alternar de uma língua para outra, se o interlocutor falar as duas línguas (OBLER; PEKKALA, 2008, p. 353 , tradução nossa $)^{3}$.

\footnotetext{
"People who master more than one language have advantages over those who master only one. [...] studies indicate that those elderly bilinguals who have lifelong experience in using two different languages have
}

Tendo em vista estas constatações, envelhescentes e pessoas da terceira idade precisam ser estimulados para aumentar a plasticidade neural, e aprender uma língua estrangeira é um incentivo perfeito para esse aumento das conexões neuronais, motivando o interesse do aprendiz da terceira idade para desenvolver outras tarefas de aprendizagem. O estímulo da plasticidade das conexões neuronais pode favorecer os envelhescentes e terceira idade nos processos de prevenção contra demência, chamando a atenção para as ações individuais de aprendizagem.

Por isso, atividades como o curso de extensão "A aula de inglês para a terceira idade" são importantes, pois os participantes são levados a conhecer a estrutura básica da língua inglesa, e também exercitam as demais habilidades linguísticas (ouvir, falar, ler, escrever) e aprendem a se comunicar em contextos situacionais, para poder assim proceder em viagens e outros objetivos pessoais com o uso da língua em questão. Uma das dificuldades enfrentadas neste curso está relacionada ao fato de que há uma diferença entre o previsto para a duração das aulas programadas e o tempo efetivo das aulas executadas. É possível que o ensino de uma segunda língua para este público - envelhescente e da terceira idade - demande de mais tempo do que para outros públicos, como crianças e adolescentes.

Considerando esta diferença de tempo programado para as aulas e o tempo efetivo, e em sendo a leitura um processo que envolve a fisiologia humana, cabe questionar se o tempo de leitura é afetado pelas condições etárias dos leitores. Para isso, realizamos um experimento de aferição de leitura oral e silenciosa de textos em inglês e português com três tipos de participantes em função da gradiência de faixa etária: jovens (23 a 35 anos), envelhescentes (45 a 59 anos) e terceira idade (60 a 84 anos). A aferição da leitura nas duas línguas - a língua materna e a segunda língua a ser aprendida, no caso, inglês, tem por objetivo identificar se há características próprias do ritmo de leitura do participante ou se é um efeito do conhecimento da língua. Para responder a essa questão, contribuindo para a formação de professores de língua inglesa para atuar com este público específico, inicialmente discorremos sobre a fisiologia da leitura e como o envelhecimento atua sobre esse processo. Em seguida, apresentamos o desenho experimental, para, por fim, trazer os resultados e conclusões da investigação.

\footnotetext{
developed better executive function and working memory, which they can more effectively use for processing language than monolingual older adults. [...] In order to overcome such naming difficulties, both monolingual and bilingual adult speakers may use different strategies such as avoidance, rephrasing, and circumlocutions. Bilingual elders, as well can borrow words from the other language or code-switch from one language to the other, if the interlocutor speaks both languages." (OBLER; PEKKALA, 2008, p. 353).
} 


\section{A fisiologia da leitura}

Do ponto de vista fisiológico, a leitura envolve diferentes estágios para o processamento da informação, com a transformação das informações recebidas pela visão ao sistema de memória fonológica, até que sejam concluídas as compreensões do sistema semântico e sua finalização (LA BERGE; SAMUELS, 1974). Estes estágios envolvem dois níveis: acurácia e automaticidade.

No primeiro nível, denominado de acurácia, é necessário que o leitor esteja atento e concentrado para processar a compreensão da leitura. Já no nível de automaticidade, não se exige tanto da memória e da sua atenção por ser um processo de respostas automáticas em relação às perguntas recebidas; o leitor faz a leitura em um procedimento experimental e discorre as informações pelas tarefas adquiridas em dissociação. Assim, a automaticidade na decodificação é o reconhecimento das pronúncias e dos significados de palavras escritas imediatamente ao vê-las, sem se dedicar atenção cognitiva ou esforço para decodificá-las (LABERGE; SAMUELS, 1974). A automaticidade refere-se à capacidade de leitura na automatização do processo de conversão grafofonológica. Se o leitor não domina essa capacidade, ela se torna um obstáculo para a compreensão do texto lido (MORAIS, 1996). Com o processamento automático, a região cerebral (occípto-temporal) que desempenha essa atividade diminui seu trabalho, liberando áreas para serem utilizadas por outras tarefas, como a compreensão do texto lido. (DEHAENE, 2012).

Dehaene releva a importância da fisiologia da mecânica humana da leitura relacionando as estratégias para decodificar cada letra, palavra, frase: "a informação visual deve ser extraída, destilada, depois recodificada num formato que restitua a sonoridade e o sentido das palavras" (DEHAENE, 2012, p. 26).

A leitura começa pelos olhos, mais especificamente, pela retina, que é a responsável pela detecção e transdução dos fótons e o seu envio, em forma de impulsos nervosos, para diferentes regiões do córtex cerebral através do nervo ótico. Existe uma região especialmente sensível na retina chamada de fóvea, que corresponde a apenas $15^{\circ}$ do campo visual e é responsável pela captura das imagens, e, por sua característica estreita, faz com que os olhos se movam incessantemente no curso da leitura. A parafóvea corresponde ao ponto de fixação em 5을 do padrão normal, na região que vai além da fóvea (DEHAENE, 2012).

Os olhos fazem movimentos discretos e contínuos para captar a informação visual, o que corresponde à capacidade de decodificar entre quatro a cinco palavras por segundo. Por conta do grau de acuidade da fóvea e da parafóvea, à medida que o campo leitor se afasta do centro do olhar, pode haver uma perda de codificação visual (DEHAENE, 2012).

No nosso sistema de leitura do português, lemos de cima para baixo e da esquerda para a direita. O movimento captor ocular percorre as frases em sacadas (ou movimento sacádico), movimentos muito curtos e rápidos, que duram em torno de 30 a $50 \mathrm{~ms}$. As sacadas oculares correspondem ao número de letras percorridas no texto, que podem ser variadas de acordo com o estilo da escrita. O número de caracteres que podemos processar na leitura é de aproximadamente entre sete a nove letras de espaço a cada sacada (VONK; COZJIN, 2003; DEHAENE, 2012).

As fixações são o ponto onde os olhos fixam; são pausas entre as sacadas, que duram em média de 200 a $250 \mathrm{~ms}$. Neste processo de sacadas e fixações, nem sempre o olhar segue palavra por palavra: Dehaene (2012) afirma que palavras gramaticais, como verbos auxiliares, pronomes, conjunções, preposições ou artigos, são quase sempre puladas, e que as outras palavras essenciais ou de conteúdo, tais como nomes, verbos, adjetivos, advérbios, costumam ser fixadas pelo olhar. Ao fazermos uma fixação, obtemos novas informações, que são incorporadas durante as sacadas da leitura do texto, que levam os olhos de um local do texto ao outro, separado novamente por uma fixação. Novas informações são decodificadas pela leitura da palavra no texto com o movimento ocular, linha a linha. Quanto à velocidade, conforme Vonk e Cozijn (2003), os leitores hábeis movem os olhos entre 7 a 9 letras de espaço em cada sacada de palavras e esses espaços contados entre letras equivalem ao valor de tempo de 200-250 ms. Essa é a padronização dos leitores hábeis, podendo haver variações no desempenho de aprendizes, e, no nosso caso, de envelhescentes.

Além das sacadas e fixações, existem os movimentos de retorno de leitura, quando os olhos movem do final da linha horizontal para o início da anterior ou da próxima linha, e a regressão de leitura, caracterizada (na leitura em língua portuguesa) por movimentos da direita para a esquerda, para regiões anteriores do texto na mesma linha ou para linhas anteriores (RAYNER; JUHASZ; POLLATESEK, 2013).

Rayner et al. (2006) afirmam que, quando crianças iniciam a leitura, suas fixações tendem a ser temporalmente mais longas do que o padrão estabelecido, próximo de $350 \mathrm{~ms}$. Leitores aprendizes também fazem duas ou três fixações por palavras (dependendo do grau de dificuldade da palavra), das quais 30\% são regressões. Contudo, as fixações são estabilizadas e a velocidade de regressões continua a cair de acordo com a evolução da idade e do conhecimento escolar. Semelhante às crianças, jovens leitores (não proficientes ou disléxicos), em todas as idades, apresentam fixações de maior duração temporal e 
sacadas mais curtas em espaço de letras e mais regressões, relativamente aos leitores hábeis em comparação com a idade. Por outro lado, o envelhecimento traz limitações fisiológicas, que implicam em um comportamento de sacadas menores em extensão de letras, por conta do enrijecimento da musculatura.

\subsection{Leitura silenciosa e em voz alta}

Nos estudos de uma segunda língua, é importante o reconhecimento inicial das palavras em leitura silenciosa e, posteriormente, em leitura em voz alta, para que os aprendizes possam ter a oportunidade de ouvir o som e experienciar a sua verbalização. Dehaene (2012) explica as duas vias de leitura simultânea:

[...] dispomos todos de uma via direta de compreendêlos. Contudo, nos leitores experientes, a sonoridade das palavras continua a ser utilizada [...] a nível mais profundo do nosso cérebro, as informações sobre a pronúncia das palavras são automaticamente ativadas. As duas vias de tratamento das palavras, a via lexical e a via fonológica, funcionam, em paralelo, uma sustentando a outra (DEHAENE, 2012, p. 40).

$\mathrm{Na}$ leitura em voz alta, o leitor deve proceder a duas tarefas simultâneas. Ele deve proceder em uma linguagem oral equivalente à linguagem escrita e ele deve também reconstruir o significado do que ele está lendo, ou seja, procurando compreender a leitura. O leitor reconhece a codificação gráfica como uma linguagem fonológica oral, em um modelo conhecido como dupla rota (COLTHEART et al., 2001). Em outro nível, dá-se a compreensão da leitura, com os processos de parsing e interação com os outros níveis da gramática (PERFETTI, STAFURA, 2014).

Como destacamos, os processos de decodificação de leitura devem ser automatizados ou bem assimilados e até mesmo chegarem ao nível de autônomos. No ensino de uma segunda língua, o processo do ensinar a decodificar é semelhante. Embora na aprendizagem tardia de uma segunda língua o conhecimento da primeira língua já esteja internalizado, o novo aprendiz segue trajetória similar, com diferentes perspectivas de desenvolvimento em função da idade, inicialmente com sacadas mais curtas em extensão de caracteres e maior duração das fixações.

\section{Leitura e envelhecimento}

Ao traçarmos uma abordagem fisiológica da leitura, temos que considerar também os efeitos do envelhecimento neste processo.

O tempo de formação de um leitor é muito longo, o que equivale ao amadurecimento desde a primeira fase de criança, na alfabetização, até a adolescência, ao final da qual a estrutura corpórea fisiológica está amadurecida e o circuito neural está formado para executar todos os procedimentos de processamento de informação (LENT, 2005; DEHAENE, 2012).

Com o passar do tempo e o envelhecimento, as pessoas em geral diminuem os ritmos de tarefas em todos os sentidos. Fisiologicamente, os músculos estão mais enrijecidos e tudo que fazemos é mais demorado. $\mathrm{Na}$ leitura, por exemplo, a retina está mais rígida, e com isso, a leitura, ao avançar da idade, começa a ficar mais lenta. O movimento ocular entre fixações (duração das sacadas) em leitura de palavras por crianças fica entre 180 a 250ms (RAYNER et al. 2006; VONK; COZIJN, 2003); não temos parâmetros para envelhecentes e terceira idade, mas é de se esperar que o tempo seja maior, dado os efeitos de envelhecimento. Obter este tipo de detalhamento sobre o processamento da leitura é importante para o planejamento de cursos e elaboração de materiais didáticos, a exemplo do curso de extensão de língua inglesa para a terceira idade.

\section{Procedimentos metodológicos}

Para mensurar o tempo de leitura, foi desenvolvido um experimento com três grupos grupos experimentais constituídos por participantes jovens, envelhecentes e terceira idade: 10 envelhescentes, na faixa etária de 45 a 59 anos, 10 da terceira idade, na faixa etária de 60 a 84 anos de idade e 10 alunos do curso de Letras Inglês da Universidade Federal de Sergipe, na faixa etária de 23 a 35 anos, que leram em voz alta e silenciosamente 20 textos em inglês e em português (cada um com cerca de 100 palavras). Os dois últimos grupos de participantes são os alunos do curso de extensão "Ensino de inglês para a terceira idade", realizado na Universidade Federal de Sergipe.

O objetivo do experimento foi mensurar o tempo de leitura em voz alta e silenciosa de textos em língua portuguesa e em língua inglesa, bem como medir o tempo e o número de fixações na leitura de textos curtos (cerca de 100 palavras) nas duas línguas. O procedimento foi apreciado e aprovado pelo CEP/CONEP, com CAAE 65725717.100005546.

Para medir o rastreamento ocular, utilizou-se equipamento de eye-tracking EyeTribe (Figura 1), com frequência $60 \mathrm{hz}$, com o módulo "pygaze-init" do software OpenSesame, para a medida de fixações na leitura silenciosa. Embora o EyeTribe seja um aparelho de baixo custo, estudos evidenciam sua acurácia para tarefas de leitura (FUNKE et al., 2016; OOMS et al., 2015). A leitura em voz alta foi registrada em áudio com o gravador digital portátil Zoom Handy Recorder, posteriormente transcrita e registrado o tempo de duração. 


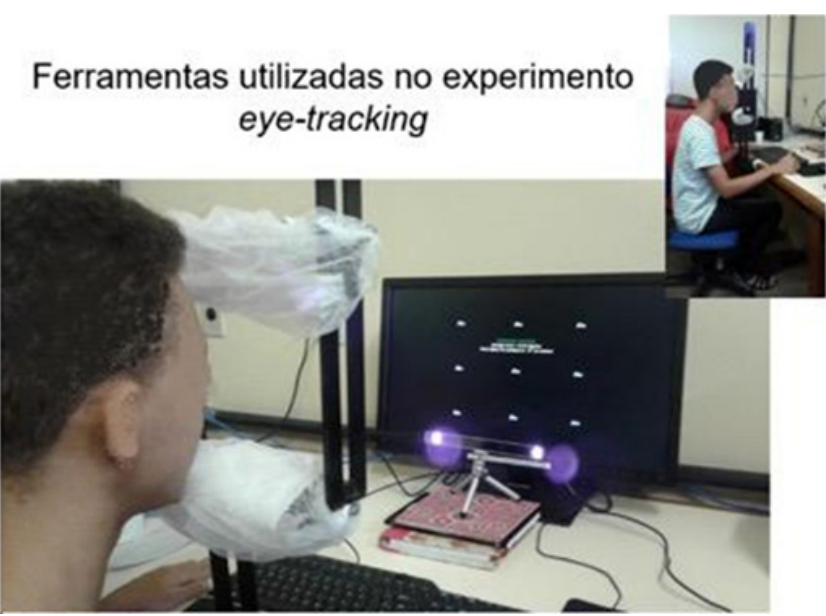

Figura 1. Posicionamento do participante durante calibragem e experimento com eye-tracker Eye Tribe.

Foram elaborados 20 textos estímulo para o experimento: dez textos em português e dez textos em inglês (Figura 2, abaixo). Dois textos desse número inicial foram selecionados para fazer a demonstração ao participante (fase pré-experimental), com o objetivo de verificar se compreendeu as explicações em relação à postura, e como dá o início da partida da leitura silenciosa. Passada esta etapa, os textos experimentais apresentavamse de forma aleatória.

O experimento foi realizado no Laboratório Multiusuário de Informática e Documentação (LAMID) da Universidade Federal de Sergipe. Após a realização, os dados foram tratados quantitativamente.

No experimento de tempo de leitura, utilizamos os parâmetros de fixações e regressões nos três grupos experimentais: jovens, envelhescentes e pessoas da terceira idade. A realização de leituras de textos, sendo dez textos em inglês e dez textos em português, permite que seja medido o tempo entre as sacadas fixações e regressões e que tenhamos um padrão de tempo de leitura para os grupos experimentais jovens, envelhescentes e terceira idade.

Os textos apresentam 68,5 palavras, em média, nos textos em português, com uma mediana de 68,0 e um desvio padrão de 10,0. Já nos textos em inglês, a média de palavras foi de 82,9 , a mediana de 79,5 e o desvio padrão de 16,5 .

Quanto à regressão, espera-se que, com o uso de estratégias de leitura (GOODMAN, 2014), os participantes façam um maior número de regressões na tentativa de compreender o texto. Conforme apontam os resultados dos estudos de Frazier e Rayner (1982), Altmann et al. (1992) e Rayner e Sereno (1994), 15\% de regressões em um total de sacadas são encontrados nas circunstâncias normais de leitura. Rayner (1998) comparou o processamento de leitura em diferentes condições, e os textos identificados como de fácil leitura são aqueles que apresentam o menor número de regressões; em condições mais difíceis, o número de regressões aumenta. Em termos de duração, o tempo de leitura em condições de dificuldades (região central, com e sem presença de conectivo) é maior do que em condições mais fáceis.

Quanto à duração das fixações, a frequência de ocorrência de sacadas e não sacadas fará com que os números fiquem relacionados à área (região) onde a medida do tempo de leitura será realizada. Isto significa que a contribuição da inclusão das durações de medidas das não-sacadas para a medida de todo o processo do tempo da região aumenta. Por isso, se houver a dificuldade do processamento, o número e duração das fixações na região aumentará.

O tamanho do texto influencia na duração do tempo das fixações, segundo Rayner (1998): quando a região de leitura for maior do que uma simples palavra que ela representa um estudo de análise, duração de efeitos de fixações por ser maior e assim ser mais apropriada em adicionar diferenças na revelação entre as condições.
13 If something bad happens, imagine how things could have 7 been worse. You will then irealize that things aren't sq bad after all. Compare your situation with other people who are in an even worse situation. Takę a long yiew of things - event if things seem bad now, expect them to get better in the end. Learn from your past mistakes and thigk of new ways of solving your problems. 27

36

42
O turismo tem um alto potencial económico, social, culturäl e ambiental que são elementos extremamente ligadós ao turismo, pois estabelecem reciprocidade entre si. 0 turismo é, pripcipalmente, grande gerador de iẻceita, é social por gerar grande número de postos de trabalho direto e indineto; cultural, pols preserva a identidade do luzar, camo monumentos históricos; e ambiental, por aliałtrenda epreservaço, um exemplo disso é o ecoturismo, quẻ só

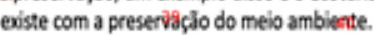
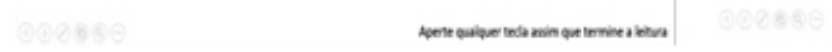

Figura 2. Telas dos textos-estímulo para a leitura, com fixações de leitura do participante CEL. 
O objetivo desta pesquisa é verificar o tempo de leitura entre os grupos participantes envelhescentes e da terceira idade em relação ao tempo dos jovens, sem aferir a compreensão da leitura. Embora os participantes façam movimentos de retorno de leitura e fixação mais demorada, possivelmente para compreender melhor o que leram, evidenciando o nível da acurácia, o objetivo do experimento, tanto da leitura silenciosa quanto em voz alta é identificar o tempo de duração da leitura, sem necessariamente aferir a compreensão.

Apresentados os parâmetros, passemos à análise do tempo de leitura silenciosa e em voz alta.

\section{Resultados e discussão}

\subsection{Leitura silenciosa e em voz alta}

As hipóteses para o controle do tempo de leitura são de que: i) todos os participantes dos grupos experimentais são mais rápidos na leitura de textos em português do que em inglês; ii) todos os participantes dos grupos experimentais são mais rápidos na leitura silenciosa do que em voz alta; e iii) participantes do grupo experimental de jovens demandam menos tempo do que os participantes do grupo experimental de envelhescentes, que por sua vez, demandam menos tempo do que os participantes do grupo experimental de terceira idade na execução destas tarefas.

Quanto aos resultados do tempo médio de leitura por palavra dos textos em inglês e em português, em voz alta e silenciosa, quanto aos três grupos experimentais: jovens, envelhescentes e terceira idade (Gráfico 1), o tempo médio de leitura entre os grupos experimentais envelhescentes e terceira idade é semelhante (tanto em

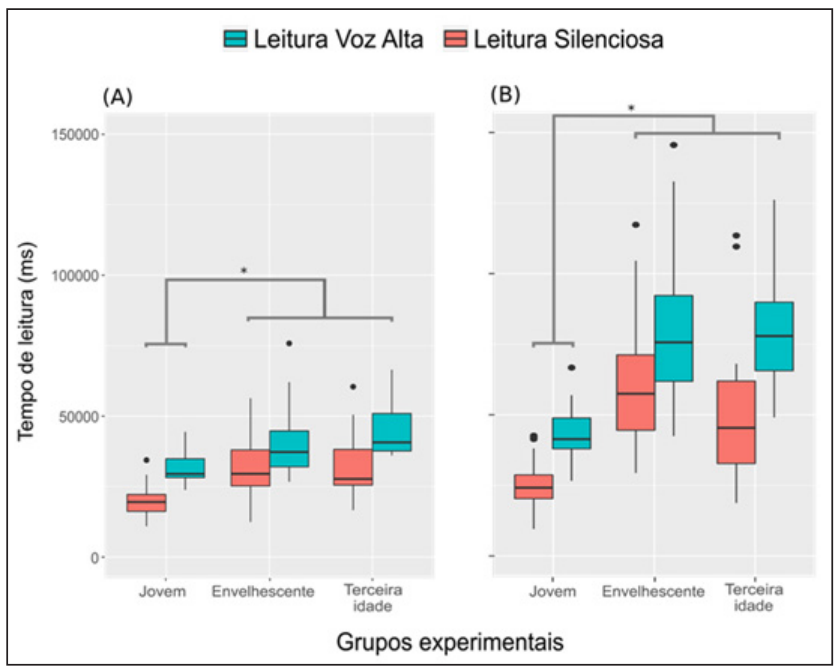

Gráfico 1. Diagrama de caixas do desempenho dos grupos experimentais quanto ao tempo médio de leitura em voz alta e silenciosa por palavra, em textos em $m(A)$ português e em (B) inglês. português quanto de inglês) e maior do que apresenta o grupo experimental jovem, nas leituras silenciosas e em voz alta ([ANOVA para os textos em Português: $\mathrm{F}_{(2,176)}=$ $38,71, \mathrm{P}<0,001 \mathrm{~F}_{(1,176)}=66,63, \mathrm{P}<0,001$ ]; [ANOVA para os textos em Inglês: $\mathrm{F}_{(2,175)}=67,10, \mathrm{P}<0,001 ; \mathrm{F}_{(1,175)}=41,48$, $\mathrm{P}<0,001])$. O grupo experimental de jovens se diferenciou dos outros dois grupos experimentais significativamente para ambas as línguas, conforme resultado de um teste ANOVA de duas vias: grupo experimental e tipo de leitura.

Vale ressaltar que, nos textos em inglês, o tempo de leitura dentre todos os grupos experimentais foi maior: somente o grupo experimental jovem apresentou tempo pouco maior em inglês do que nas leituras em português. Já os grupos experimentais de envelhescentes e da terceira idade leram os textos em inglês em voz silenciosa mais rápido do que o texto em voz alta. No entanto, alguns dos participantes destes grupos experimentais tiveram um comportamento fora do padrão estabelecido, o que pode ser observado pela presença marcante da linha vertical, como pode ser verificado no Gráfico 1).

$\mathrm{O}$ resultado permite afirmar que houve diferenças entre os grupos experimentais. As hipóteses sobre o tempo de leitura de envelhescente e pessoa da terceira idade ser maior do que a leitura de um jovem se confirmam diante dos dados apresentados: nos textos em português, o grupo experimental da terceira idade demonstrou necessitar de mais tempo do que os demais grupos experimentais, mostrando uma variação. No entanto, o grupo experimental dos envelhescentes parece gastar mais tempo do que o grupo experimental da terceira idade, mas essa diferença não é significativa.

A leitura silenciosa demanda menor tempo do que a leitura em voz alta devido à preocupação do leitor em articular os fonemas de acordo com os traços fonológicos da língua. $\mathrm{O}$ tempo de leitura silenciosa é menor devido à não preocupação da pronúncia das palavras. Já nos textos em inglês, o tempo foi muito maior. $\mathrm{O}$ grupo experimental da terceira idade apresentou um tempo muito maior, equivalente a aproximadamente $500 \mathrm{~ms}$, e, na leitura em voz alta, aproximadamente 600-650ms. Já para o grupo experimental dos envelhescentes, o tempo foi superior ao tempo demandado pelo grupo experimental da terceira idade, o que demonstra uma dispersão do tempo de leitura. $\mathrm{O}$ grupo experimental de envelhescentes apresentou maior dispersão no registro do tempo das tarefas executadas, assim como o grupo experimental da terceira idade, a exemplo do resultado da leitura silenciosa (aproximadamente a $600-700 \mathrm{~ms}$ ) para a leitura em voz alta. Este grupo experimental também apresenta tempo médio muito maior do o grupo experimental da terceira idade (com aproximadamente $200 \mathrm{~ms}$ ); não obstante, esta diferença não é significativa, como aponta a ANOVA. 
A diferença de tempo encontrada entre os grupos experimentais confirma a hipótese levantada, no entanto, convém destacar que o tempo de diferença de leitura entre os grupos experimentais de envelhescentes e terceira idade em relação aos jovens está na casa de milissegundos. Esta diferença pode ser crucial, por exemplo, para a concessão de carteira de habilitação (na medida em que milissegundos de diferença podem levar a um acidente de trânsito), mas em uma aula de 60 minutos, por exemplo, embora essa diferença exista, comprovando o que a literatura aponta quanto ao aumento da demanda de tempo na execução de tarefas decorrente do envelhecimento, os milissegundos de diferença não interferem na aula de inglês. Este resultado é importante para desmistificar o fato de que "idosos" são mais lentos e que por isso teriam dificuldades de aprender ou precisariam de mais tempo para executar atividades de leitura (eles precisam, mas o tempo demandado não influencia no conjunto geral de uma aula).

\subsection{Número de fixações}

As hipóteses para o controle do número de fixações durante a leitura são de que participantes do grupo experimental dos mais jovens fazem menos fixações (com sacadas mais longas) do que os participantes do grupo experimental de envelhescentes, que, por sua vez, fazem menos fixações do que os participantes do grupo experimental de terceira idade, em função das limitações fisiológicas do envelhecimento (enrijecimento da musculatura).

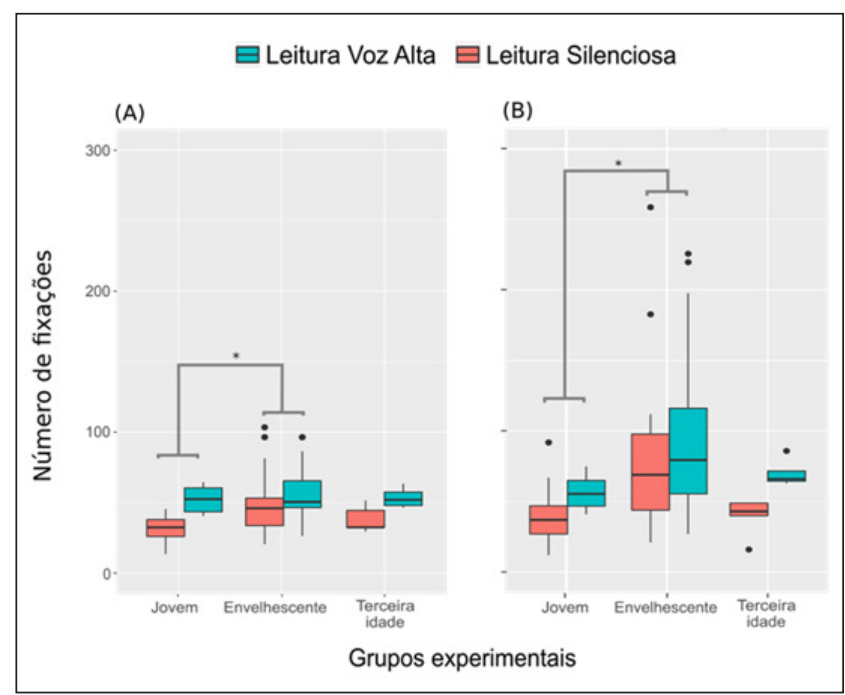

Gráfico 2. Diagrama de caixas do desempenho dos grupos experimentais quanto ao número de fixações, em textos em (A) português e em (B) inglês.
Identificamos que houve diferença entre os grupos de jovens e envelhescentes, corroborando parcialmente a hipótese levantada (Gráfico 2). A terceira idade obteve um número de fixações menor do que o dos envelhescentes, que obtiveram um número bastante acentuado de fixações. A realização de um teste ANOVA de duas vias, grupo e tipo de leitura, apontou que só os grupos experimentais jovens e envelhescentes tiveram diferenças significativas no número de fixações ([ANOVA para os textos em Português: $\mathrm{F}_{(2,122)}=10,70, \mathrm{P}<0,001 ; \mathrm{F}_{(1,122)}=24,12$, $\mathrm{P}<0,001$ ]; [ANOVA para os textos em Inglês: $\mathrm{F}_{(2,121)}=$ 9,827, $\left.\left.\mathrm{P}<0,001 ; \mathrm{F}_{(1,121)}=1,345, \mathrm{P}>0,05\right]\right)$.

Quanto aos participantes em relação aos grupos experimentais jovens, envelhescentes e terceira idade, as fixações foram mais executadas pelo grupo experimental de envelhescentes do que pelo grupo experimental de da terceira idade. Já o grupo experimental de jovens apresentou menor número de fixações. Este resultado só permite afirmar que houve diferenças entre os grupos experimentais; um grupo mostrou um número de fixação menor do que o outro. Lembramos que não estamos analisando a leitura com compreensão e sim o tempo da leitura. A linha vertical mostra que houve uma diferença muito maior entre os membros dos mesmos grupos experimentais.

Rayner (1998) aponta que até mesmo os leitores hábeis fazem regressões diante de algumas dificuldades da língua, como em estruturas ou frases mais elaboradas. Leitores em geral fazem mais fixações, menos sacadas e mais regressões. Em crianças, as fixações tendem a ser em $350 \mathrm{~ms}$. E também $30 \%$ de suas fixações por palavras vão depender do tamanho da palavra, isto é, a sua quantidade de sílabas e, além disso, 30\% dessas fixações são regressões. Os leitores costumam pular, traçar ou omitir palavras durante a leitura, mas mesmo assim, no contexto, isso não é prejudicial à compreensão. A duração da fixação na palavra pode trazer indícios de compreensão quanto ao contexto, tempo, sintaxe. Adicionamos também o fator escolaridade e habitualidade de leitura, que são informações relevantes que poderiam ser observadas.

Embora os estudos de Vonk e Cozjin (2003) e Rayner et al. (2006) sugiram que os leitores façam a compreensão do texto durante a leitura, eles também alertam para as várias intercorrências sobre o movimento ocular, que refletem no tempo de fixação o processo dos leitores em obter significado. Outra observação pode estar relacionada ao estado emocional de cada pessoa, assim como também toda a preparação antecedente aos experimentos como: óculos, maquiagem, transplante das córneas ou catarata.

$\mathrm{O}$ fato de os grupos experimentais de envelhescentes terceira idade realizarem mais fixações aponta para a necessidade de se considerar este fator na hora de desenvolver materiais didáticos de suporte à leitura, com 
uma diagramação que permita movimentos confortáveis de sacadas (mancha da página mais estreita, por exemplo).

\subsection{Duração das fixações}

Do mesmo modo que para o número de fixações, as hipóteses para o controle desta variável são de que participantes do grupo experimental dos jovens fazem fixações com maior duração do que os participantes do grupo experimental dos envelhescentes, que, por sua vez, fazem fixações com maior duração do que os participantes do grupo experimental da terceira idade.

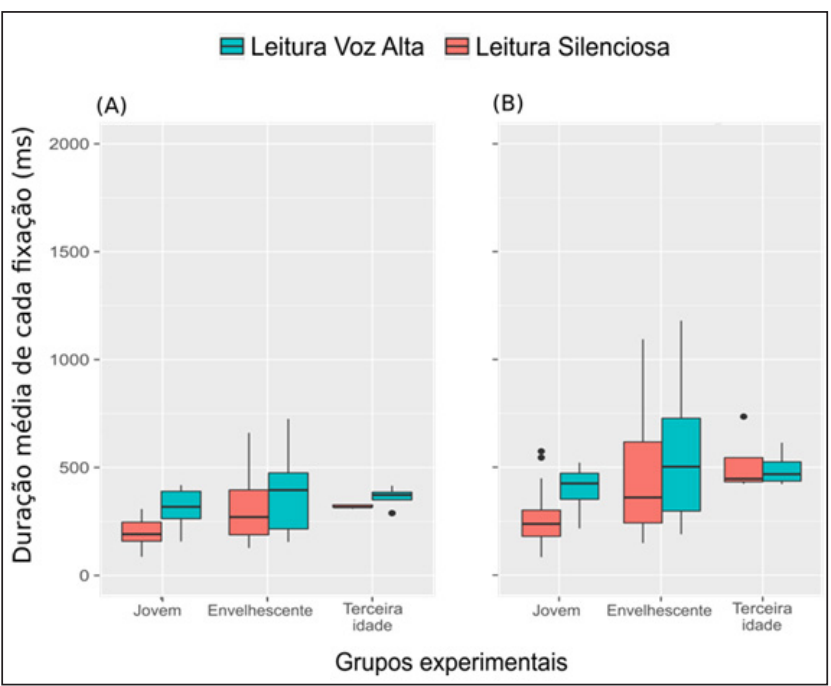

Gráfico 3. Diagrama de caixa do desempenho dos grupos experimentais quanto à duração média das fixações, em textos em ( $A$ ) português e em (B) inglês.

O quadro comparativo de duração média da fixação em ms na leitura de inglês, entre as categorias jovens, envelhescentes e da terceira idade (Gráfico 3), constatamos que os envelhescentes apresentaram uma duração média maior que as outras duas categorias; contudo, as diferenças não são significativas ([ANOVA para os textos em Português: $\mathrm{F}_{(2,122)}=0,17, \mathrm{P}=0,844$; $\mathrm{F}_{(1,122)}=0,403, \mathrm{P}=0,527$ ]; [ANOVA para os textos em Inglês: $\mathrm{F}_{(2,121)}=0,960, \mathrm{P}=0,386 ; \mathrm{F}_{(1,121)}=1,117$, $\mathrm{P}=0,293])$, o que não corrobora a hipótese da perda de acurácia, devido à idade.

\section{Considerações finais}

Com a investigação do tempo de leitura silenciosa e em voz alta, constatamos que, embora existam diferenças entre os grupos experimentais, esse tempo, em milissegundos, não é suficiente para justificar a hipótese inicial de que os grupos experimentais de envelhescentes e da terceira idade precisam de mais tempo para o desempenho das tarefas a serem executadas em leitura. Como dissemos, esse resultado em milissegundos pode ser relevante no caso de uma concessão de carteira de habilitação (um milissegundo de diferença pode causar um acidente, por exemplo), mas não para a participação em uma aula de inglês.

$\mathrm{O}$ resultado ajuda a desfazer o mito de que pessoas mais velhas são mais lentas e que por isso teriam mais dificuldades, necessitando de mais tempo para as atividades. A investigação do número e da duração das fixações durante o movimento de leitura apontou que os grupos experimentais de envelhescentes e da terceira idade realizam mais fixações com uma duração média maior. Os participantes do grupo experimental de jovens fazem menos fixações do que os dos grupos experimentais de envelhescentes e da terceira idade, o que é natural da idade, devido à fisiologia humana e perdas da plasticidade muscular, o que explica essa diferença do tempo de leitura.

Os resultados também corroboram a hipótese da perda de acurácia devido à idade, pois, como vimos, fisiologicamente, músculos mais enrijecidos necessitam de um maior tempo. Em termos de formação de professores para atuarem com esse público, podemos destacar a necessidade de se considerar esse fator na hora de desenvolver materiais didáticos de suporte à leitura, com uma diagramação que permita movimentos confortáveis de sacadas (mancha da página mais estreita, por exemplo). Novas pesquisas precisam ser empreendidas nesse campo.

Reforçamos que ensinar inglês para envelhescentes e pessoas da terceira idade é diferente de ensinar para crianças e adolescentes, tradicional público-alvo dos cursos de formação de professores. Em suma, os resultados deste estudo evidenciam a necessidade de uma formação diferenciada para os profissionais que irão atuar com esse tipo de público, abrindo novos nichos de mercado de trabalho, e atendendo a uma demanda de política pública, haja vista a inversão da pirâmide etária da população brasileira.

\section{Referências}

ALTMANN, Gerry, et al.. Avoiding the garden path: Eye movements in context. Journal of Memory and Language, v. 31, n. 5, p. $685-712,1992$.

BIALYSTOK, Ellen, et al. Dual-modality monitoring in a classification task: The effects of bilingualism on aging. The Quaterly Journal of Experimental Psychology, v. 59, n. 11, p. 1968-1983, 2006

BIALYSTOK, Ellen. Bilingualism in Development: Language, Literacy \& Cognition. Cambridge: Cambridge University Press, 2001 
BRASIL. Instituto Brasileiro de Geografia e Estatística. Censo Demográfico - 2010. Rio de Janeiro: IBGE. Disponível em: $<$ https://censo2010.ibge.gov.br/>. Acesso em: 15 jul. 2016.

COLTHEART, Max et al. DRC: a dual route cascaded model of visual word recognition and reading aloud. Psychological review, v. 108, n. 1, p. 204-256, 2001.

DEHAENE, Stanislas. Os neurônios da leitura: como a ciência explica a nossa capacidade de ler. Tradução: Leonor Scliar Cabral, Porto Alegre: Penso, 2012.

FRAZIER, Lyn; RAYNER, Keith. Making and correcting errors during sentence comprehension: Eye movements in the analysis of structurally ambiguous sentences. Cognitive Psychology, v. 14, n. 2 , p. $178-210,1982$.

FUNKE, Gregory et al. Which Eye Tracker Is Right for Your Research? Performance Evaluation of Several Cost Variant Eye Trackers. In: Proceedings of the Human Factors and Ergonomics Society Annual Meeting. Los Angeles: SAGE Publications, 2016. p. 1240-1244.

GOODMAN, Kenneth S. Reading: A psycholinguistic guessing game. In: GOODMAN, Kenneth S.; GOODMAN, Yetta M. (Org.). Making sense of learners making sense of written language: The selected works of Kenneth S. Goodman and Yetta M. Goodman. Routledge, 2014. p. 115-124.

LABERGE, David; SAMUELS, S. Jay. Toward a theory of automatic information process in reading. Cognitive Psychology, v. 6, n. 2, p. 293-323, 1974.

LENT, Robert. Cem bilhões de neurônios: conceitos fundamentais de neurociência. São Paulo: Atheneu, 2005.

MORAIS, José. A arte de ler. São Paulo: EdUnesp, 1996.

OBLER, Loraine K.; PEKKALA, Seija. Language and Communication in Aging. In: STEMMER, Brigitte; WHITAKER, Harry A. (Org.). Handbook of the Neuroscience of Language. London: Academic Press, 2008. p. 351-358.

OOMS, Kristien et al. Accuracy and precision of fixation locations recorded with the low-cost Eye Tribe tracker in different experimental setups. Journal of eye movement research, v. 8, n. 1, p. 1-24, 2015.
PERFETTI, Charles; STAFURA, Joseph. Word knowledge in a theory of reading comprehension. Scientific Studies of Reading, v. 18, n. 1, p. 22-37, 2014.

PORTO, Maria Augusta Rocha. Um ensino do idioma inglês: seu papel na inclusão social. Interdisciplinar: Revista de Estudos de Língua e Literatura, v. 17, p. 469-478, 2012.

RAYNER, Keith et al. Eye movements as reflections of comprehension processes in reading. Scientific studies of reading, v. 10, n. 3, p. 241-255, 2006.

RAYNER, Keith; JUHASZ, Barbara J.; POLLATSEK, Alexander. Movimentos Oculares durante a leitura. In: SNOWLING, Margaret J.; HULME, Charles (Org.). A ciência da leitura. Porto Alegre: Penso, 2013. p. 97-116.

RAYNER, Keith; SERENO, Sara C. Regressive eye movements and sentence parsing: On the use of regression-contingent analyses. Memory \& Cognition, v. 22, n. 3, p. 281-285, 1994.

RAYNER, Keith. Eye Movements in Reading and Information Processing: 20 Years of Research. Psychological Bulletin, n. 124, p. 372-422, 1998.

SCHLEGEL, Alexander A.; RUDELSON, Justin J.; TSE, Peter U. White matter structure changes as adults learn a second language. Journal of cognitive neuroscience, v. 24, n. 8, p. 1664-1670, 2012.

TOMITCH, Leda Maria Braga. A implementação de processos de leitura no cérebro humano: desvelando a compreensão leitora. Letras de Hoje, v. 48, n. 3, p. 309-315, 2013.

VONK, Wietske; COZIJN, Reinier. On the treatment of saccades and regressions in eye movement measures of reading time. In: RADACH, Ralph; HYONA, Jukka; DEUBEL, Heiner (Org.). The mind's eye: Cognitive and applied aspects of eye movement research. London: Elsevier, 2003. p. 291-311.

Recebido: 28/09/2017

Aprovado: 17/04/2018

Contato:

Maria Augusta Rocha Porto <mariaaugusta.porto@gmail.com> 